\title{
Progress Made in Lunar In-Situ Resource Utilization under NASA's Exploration Technology and Development Program
}

\author{
G.B. Sanders ${ }^{1}$, W.E. Larson ${ }^{2}$ \\ ${ }^{1}$ NASA/Johnson Space Center, Houston, TX, 77058, USA; (281) 483-9066; \\ gerald.b.sanders@nasa.gov \\ ${ }^{2}$ NASA/Kennedy Space Center, Cape Canaveral, FL, 32899, USA; (321) 867-8747; \\ william.e.larson@nasa.gov
}

\begin{abstract}
Incorporation of In-Situ Resource Utilization (ISRU) and the production of mission critical consumables for 9 propulsion, power, and life support into mission architectures can greatly reduce the mass, cost, and risk of missions 10 leading to a sustainable and affordable approach to human exploration beyond Earth. ISRU and its products can 11 also greatly affect how other exploration systems are developed, including determining which technologies are 12 important or enabling. While the concept of lunar ISRU has existed for over 40 years, the technologies and systems 13 had not progressed much past simple laboratory proof-of-concept tests. With the release of the Vision for Space 14 Exploration in 2004 with the goal of harnessing the Moon "s resources, NASA initiated the ISRU Project in the 15 Exploration Technology Development Program (ETDP) to develop the technologies and systems needed to meet 16 this goal. In the five years of work in the ISRU Project, significant advancements and accomplishments occurred in 17 several important areas of lunar ISRU. Also, two analog field tests held in Hawaii in 2008 and 2010 demonstrated 18 all the steps in ISRU capabilities required along with the integration of ISRU products and hardware with 19 propulsion, power, and cryogenic storage systems. This paper will review the scope of the ISRU Project in the 20 ETDP, ISRU incorporation and development strategies utilized by the ISRU Project, and ISRU development and 21 test accomplishments over the five years of funded project activity.
\end{abstract}

\section{INTRODUCTION}

In the Vision for Space Exploration released by the United States President in 2004 , it stated that NASA must "...develop new technologies and harness the moon's abundant resources to allow manned exploration of more challenging environments." By harnessing space resources, explorers would not have to bring everything from Earth as they did for the Apollo missions, thereby either reducing the total mass of hardware launched from Earth or increasing what can be accomplished with the same launch vehicle. While the concept of utilizing resources at the site of exploration, commonly referred to as In-Situ Resource Utilization (ISRU), had been proposed before the first man walked on the Moon, development of this capability had not progressed much past feasibility tests under laboratory conditions during the subsequent forty years. In 2005, NASA created the ISRU Project in the Exploration Technology and Development Program (ETDP). 
The purpose of this project was to:

- Develop technologies, hardware, and systems to Technology Readiness Level (TRL) 6

- Mitigate the risk of utilizing ISRU in future robotic and human missions to the Moon, Mars, \& beyond

- Coordinate development of ISRU technologies and systems with other exploration systems

- Coordinate insertion of ISRU capabilities into architecture and mission plans.

The ISRU Project was led first by the NASA Johnson Space Center (JSC), and then by the Kennedy Space Center (KSC), and involved personnel from the Marshall Space Flight Center (MSFC), Glenn Research Center (GRC), Ames Research Center (ARC), and the Jet Propulsion Laboratory (JPL). Significant work was also performed by industry and academia through contracts, grants, Small Business Innovative Research (SBIR), and Internal Research and Development (IR\&D).

\section{IN-SITU RESOURCE UTILIZATION}

The purpose of In-Situ Resource Utilization is to harness and utilize resources at the site of exploration (both natural and discarded) to create products and services that reduce the mass, cost, and risk of robotic and human exploration as well as increase performance or enable new mission concepts compared to bringing everything from Earth. The immediate goal of ISRU is to greatly reduce the direct expense of humans going to and returning from the Moon and Mars, and then to build toward self-sufficiency of long-duration crewed space bases to expand our exploration efforts, and to enable the commercialization of space. Five major areas of ISRU that have been shown to have great interest and benefit to future robotic and human exploration architectures are:

1. Resource Characterization and Mapping (physical, mineral/chemical, and volatiles/water)

2. Mission Consumable Production (propellants, fuel cell reagents, life support consumables, and feedstock for manufacturing \& construction)

3. Civil Engineering \& Surface Construction (radiation shields, landing pads, habitats, etc.)

4. Energy Generation, Storage, and Transfer with In-situ Resources (solar, electrical, thermal)

5. Manufacturing and Repair with In-situ Resources (spare parts, wires, trusses, systems etc.)

ISRU is a capability involving multiple technical discipline elements including mobility, regolith manipulation, regolith processing, chemical and thermal processing, product separation and storage \& delivery, power, and manufacturing.

\section{IMPACT OF ISRU ON OTHER SYSTEMS AND ELEMENTS IN LUNAR ARCHITECTURES}

Today, missions must bring all of the propellant, air, food, water, habitable volume, and shielding needed to sustain human explorers for trips beyond Earth. Resources for production of propellants and life support consumables along with 
feedstock for construction of support systems and habitats must be found in space and utilized if humans ever hope to explore and colonize space beyond Earth.

ISRU capabilities and systems cannot exist on their own. By definition, ISRU systems must connect and tie to one or more users to deliver desired capabilities and products. Therefore, the benefit of incorporating ISRU into mission plans is directly related to the extent to which it is used and when it is used. Without ISRU, exploration missions must bring everything needed to sustain astronauts from the surface of the Earth. Because human exploration missions require significant amounts of oxygen, water, and fuel, incorporation of ISRU into missions has primarily focused on extracting or producing these mission critical consumables.

What is not often readily apparent to architecture and mission planners is that the incorporation of ISRU and the products it creates can strongly influence architecture choices as well as the design, development, and operation of surface and transportation systems. From an architectural perspective, incorporation of ISRU and its products can greatly change (for the better) the following architectural decisions.

- Level of reusability (none or multi-use)

- Duration of stay on surface (short vs. long/permanent)

- Level of protection for crew and hardware (radiation and debris shielding)

- Location of exploration (resources, sunlight, environment)

- Commercial involvement (production of consumables, power, transportation, construction, depots)

- Mission Staging (Earth Orbit, Earth-Moon L1/L2, Low Lunar Orbit, Lunar Surface)

- Pre-deployment (set up before crew arrives or all at once)

- Abort strategies (To orbit and back to Earth or to surface and wait)

- Hub-and-spoke surface exploration from a centralized base or all missions to different lunar locations launched from Earth

Incorporation of ISRU and its products can also greatly affect how other exploration systems are developed, including determining which technologies are important or enabling. Table 1 below depicts design requirements that are impacted or shared with ISRU systems linked to the exploration system as well as what technologies and hardware can potentially be shared between the exploration system and corresponding ISRU process. 
Table 1. Impact of ISRU on Exploration System Requirements and Hardware

\begin{tabular}{|c|c|c|}
\hline & Requirements Impacted or Shared & Hardware Impacted or Shared \\
\hline Propulsion & $\begin{array}{l}\text { Type of propellant and/or pressurant } \\
\text { Quantity and production rate of propellant/pressurant } \\
\text { Propellant storage quality (temperature \& pressure) }\end{array}$ & $\begin{array}{l}\text { Propellant/pressurant storage tanks and valves } \\
\text { Propellant/pressurant transfer } \\
\text { Solar collectors }\end{array}$ \\
\hline $\begin{array}{l}\text { Life Support \& } \\
\text { EVA Systems }\end{array}$ & $\begin{array}{l}\text { Type of life support consumables } \\
\text { Quantity and production rate of consumables } \\
\text { Waste products and trash type } \\
\text { Waste products and trash quantity } \\
\text { Consumable storage quality (temperature \& pressure) }\end{array}$ & $\begin{array}{l}\text { Consumable storage tanks and valves } \\
\text { Water processing/electrolysis } \\
\text { Waste/trash processing } \\
\text { Carbon dioxide processing } \\
\text { Reactant/product seperation } \\
\text { Consumable transfer } \\
\text { Solar collectors } \\
\end{array}$ \\
\hline Habitat & $\begin{array}{l}\text { Shielding and protection for crew and equipment } \\
\text { Inflation gas quantity and type } \\
\text { Thermal management }\end{array}$ & Structure and shielding concepts \\
\hline Surface Mobility & $\begin{array}{l}\text { Mobility vehicle size } \\
\text { Mobility vehicle terrain and environment compatibility } \\
\text { Mobility power requirements }\end{array}$ & $\begin{array}{l}\text { Mobile platforms for excavation \& civil enginerring } \\
\text { Actuators, motors, and control software }\end{array}$ \\
\hline Power & $\begin{array}{l}\text { Daytime power amount (nominal \& maximum) } \\
\text { Nightime/eclipse power amount } \\
\text { Fuel cell reactant type } \\
\text { Quantity and production rate of fuel cell reactants } \\
\text { Fuel cell reactant storage quality (temp \& pressure) }\end{array}$ & $\begin{array}{l}\text { Consumable storage tanks and valves } \\
\text { Water processing/electrolysis } \\
\text { Propellant/pressurant transfer } \\
\text { Reactant/product seperation } \\
\text { Consumable transfer } \\
\text { Solar collectors/thermal energy storage and transfer }\end{array}$ \\
\hline Science & $\begin{array}{l}\text { Sample mineral characterization and mapping } \\
\text { Sample physical characterization } \\
\text { Sample volatile characterization and mapping }\end{array}$ & $\begin{array}{l}\text { Science instruments } \\
\text { Subsurface sample access } \\
\text { Test gases and reagents for science }\end{array}$ \\
\hline
\end{tabular}

\section{INCORPORATION STRATEGY}

The ability to harness and utilize space resources has been listed as an important goal in numerous NASA and international strategic planning and architecture studies. To achieve the greatest benefit of utilizing ISRU systems in robotic and human exploration missions, it is important to consider incorporation of ISRU products from the start in architecture and mission planning, since the benefit of incorporating ISRU is directly related to the extent to which it is used and when it is used. When considering strategies on how best to incorporate ISRU into future mission plans, it is important to consider how to mitigate the risk associated with ISRU systems, especially since they have not been used in any previous robotic or human missions. One approach is to consider technical and performance risk reduction strategies, the other is to consider mission risk reduction with respect to mission success.

For incorporation strategies dealing with technical and performance risk reduction, it is important to start with the minimum of infrastructure required and the simplest systems possible. Efficiency and performance increases should be evolutionary based on lessons learned from previous work. Early hardware needs to be achievable (not necessarily optimized) and scalable to future missions and outpost growth. Use of terrestrial analog field tests, robotic precursor missions, and predeployment of hardware allows for incremental reduction in technical and performance risks. ISRU capabilities need to grow on an as-needed basis with the growth and expansion of surface activities. For example, surface construction and 
manufacturing will start with simple/high leverage products and expand to greater self-sufficiency capabilities over time.

For incorporation strategies dealing with risk reduction for mission success, the approach utilized for the Constellation Program and the Global Point of Departure (GPoD) lunar architecture with the International Space Exploration Coordination Group (ISECG) was to identify ISRU capabilities and technologies that could meet one or more of the following criteria: (i) reduce mission mass and risk, (ii) help solve limitations to the architecture, (iii) enable long-term sustainability, and/or (iv) support future Mars exploration activities. The ISRU capabilities identified would then be incorporated into mission plans by first demonstrating the feasibility of the ISRU system through proof-of-concept demonstrations on robotic precursor or early human missions, and then through deployment of pilot scale operations. These pilot scale ISRU systems would be used to enhance or extend mission capabilities and/or reduce mission risk. If possible, ISRU systems were pre-deployed and operated remotely before the crew arrived to ensure that ISRU products were available at the start of the mission before the crew left Earth. Once the pilot ISRU system had adequately verified production rates, reliability, and long-term operations, full scale ISRU systems for mission critical operations could be implemented. Once a central exploration base is selected, ISRU incorporated into missions must ensure a constant delivery of products, with incremental growth in both the number of products and quantity of products.

\section{LUNAR RESOURCES \& ISRU DEVELOPMENT}

Lunar exploration mission concepts primarily consider the use of lunar regolith, solar wind volatiles, and potentially water ice and other volatiles at the lunar poles for the production of propellants, life support consumables, radiation shields, and habitat/infrastructure construction. Before recent findings of water on the Moon, most lunar mission trade study and design efforts that included ISRU focused on the production of oxygen from oxygen bearing ores in lunar regolith, and removal of solar wind deposited elements. The lunar regolith is primarily made up of four major mineral types: pyroxene, anorthite, olivine, and ilmenite, and over $42 \%$ by mass of lunar regolith is oxygen. Table 2 depicts the major constituents of lunar mare samples and solar wind volatiles released from Apollo samples. The table also depicts the major volatiles released after the impact of the Lunar Crater Observation

\& Sensing Satellite (LCROSS). Examining regolith and solar wind volatile constituents in Table 2, the Moon is poor in carbon resources. However, trash, waste, and discarded composite structures are carbon rich, and the potential for carbon monoxide and other hydrocarbons in polar shadowed areas are also important resources for sustained human lunar exploration.

Based on what is known about the resources present on the Moon (both natural and discarded), and the uncertainties associated with the form and concentration of water and other volatiles at the lunar poles, the ISRU Project in ETDP focused on developing technologies and systems in the following areas:

- Polar Ice/Volatile Resource Characterization and Mapping

- Extraction of Oxygen from Lunar Regolith

- Excavation of Lunar Regolith for Oxygen Extraction and Civil Engineering 
- Fuel/Water Production from In-Situ Carbon Sources

To support design and hardware development in these three task areas, the ISRU Project in ETDP also initiated work in the following areas:

- Lunar Simulant Development and Production

- Process and System Modeling

- Integrated Testing and Facilities

Table 2. Lunar Regolith and Volatile Constituents [1,2]

\begin{tabular}{|c|c|c|c|}
\hline \multicolumn{2}{|c|}{ Mare Regolith } & \multicolumn{2}{|c|}{ Solar Wind Volatiles } \\
\hline Pyroxene & $50 \%$ & Hydrogen & $50-150 \mathrm{ppm}$ \\
\hline $\mathrm{CaO} * \mathrm{SiO}_{2}$ & $36.7 \%$ & Helium & $3-50 \mathrm{ppm}$ \\
\hline $\mathrm{MgO}^{*} \mathrm{SiO}_{2}$ & $29.2 \%$ & Helium-3 & $10-2 \mathrm{ppm}$ \\
\hline $\mathrm{FeO}^{*} \mathrm{SiO}_{2}$ & $17.6 \%$ & Carbon & $100-150 \mathrm{ppm}$ \\
\hline $\mathrm{Al}_{2} \mathrm{O}_{3} * \mathrm{SiO}_{2}$ & $9.6 \%$ & & \\
\hline $\mathrm{TiO}_{2} * \mathrm{SiO}_{2}$ & $6.9 \%$ & \multicolumn{2}{|c|}{ Major Volatiles from LCROSS } \\
\hline Anorthite & $20 \%$ & Carbon Monoxide & $5.70 \%$ \\
\hline $\mathrm{CaO}^{*} \mathrm{Al}_{2} \mathrm{O}_{3} * \mathrm{SiO}_{2}$ & $97.7 \%$ & Water/Ice & $5.50 \%$ \\
\hline Olivine & $15 \%$ & Hydrogen & $1.40 \%$ \\
\hline $2 \mathrm{MgO}^{*} \mathrm{SiO}_{2}$ & $56.6 \%$ & Hydrogen Sulfide & $0.92 \%$ \\
\hline $2 \mathrm{FeO} * \mathrm{SiO}_{2}$ & $42.7 \%$ & Mercury & $0.48 \%$ \\
\hline Ilmenite & $15 \%$ & Ammonia & $0.33 \%$ \\
\hline $\mathrm{FeO} * \mathrm{TiO}_{2}$ & $98.5 \%$ & & \\
\hline
\end{tabular}

\section{Polar Ice/Volatile Resource Characterization}

The presence of large amounts of water, hydrogen, and hydrocarbon resources at the poles could provide significant benefits for life support, propulsion, power, thermal control, food production and manufacturing. While orbital data sets and the LCROSS impact have provided important information about the volatiles that exist in the shadowed regions at the poles, there is still tremendous uncertainty in the form, concentration, and distribution of these resources on a local scale as well as the environment and terrain associated with gaining access to these resources. Because of this uncertainty, the ISRU Project initiated work in developing instruments and equipment that could serve as a payload for a robotic precursor mission to answer fundamental science questions, such as "What resources are available on the Moon, where are they, and in what form?" as well as critical engineering questions, such as "How will we mine these resources, what chemical extraction processes are the most practical and efficient, and what are the engineering challenges to be faced in this environment?".

\section{Extraction of Oxygen from Lunar Regolith}

Over 20 different concepts for extracting oxygen from metal and non-metal oxides in the lunar regolith have been proposed and in several cases, subscale proofof-concept tests have been performed in the laboratory. Each process has strengths and weaknesses in terms of extraction efficiency, energy required, and complexity of operations. At the start of the ISRU Project in 2005, it was decided that three oxygen extraction from regolith concepts would be pursued that spanned the range of low risk/low performance to high risk/high performance techniques. 
The low risk/low performance technique selected was the Hydrogen Reduction of regolith process. This process heats regolith to $\sim 900{ }^{\circ} \mathrm{C}$ (below the sintering temperature of regolith) in the presence of hydrogen. The hydrogen reacts with iron oxides in the regolith to form water. The water is electrolyzed with the oxygen stored for later use and the hydrogen is recycled for further regolith reduction. The process is low risk since the regolith remains granular during all of the processing steps, and fluidized beds and water electrolysis are understood processing techniques. The process is low performance since iron oxide bearing minerals are found in low concentrations in lunar regolith, especially at the poles, so only about 1 to $3 \mathrm{~kg}$ of oxygen can be extracted from every $100 \mathrm{~kg}$ of bulk regolith. Size sorting and mineral beneficiation techniques can increase the surface area and concentration of iron oxide in the feedstock such that performance can be improved.

The mid risk/mid performance technique selected was the Carbothermal Reduction of regolith process. This process heats regolith past the melting point $\left(>1600{ }^{\circ} \mathrm{C}\right)$ in the presence of methane. The methane cracks releasing carbon into the melt which reacts with oxygen in the silicates to release carbon monoxide. The carbon monoxide and hydrogen released during cracking are reacted in a catalytic reactor to create methane and water. As before, the water is electrolyzed with oxygen stored for later use and the hydrogen recycled to remake the methane reactant. The process is mid risk because the regolith has to be melted and managed. The process is mid performance since silicates make up a large fraction of lunar regolith and proof-of-concept tests have demonstrated extraction efficiencies equivalent to 10 to $20 \mathrm{~kg}$ of oxygen per $100 \mathrm{~kg}$ of bulk regolith.

The high risk/high performance technique selected for development was molten oxide electrolysis. This process heats regolith past the melting point in the presence of a cathode, anode, and electrical current. The current electrolyzes several metal/non-metal oxides releasing pure oxygen gas. The process can also produce pure iron, silicon, and other metals depending on the voltage applied. The process is high risk due to the need to contain and process molten materials, molten metals, and pure oxygen at high temperatures. The process is high performance since oxygen production equivalent to 20 to $30 \mathrm{~kg}$ of oxygen per $100 \mathrm{~kg}$ of bulk regolith are possible.

\section{Excavation of Lunar Regolith for Oxygen Extraction and Civil Engineering}

Based on lunar architecture studies performed to date, there are five possible regolith excavation and civil engineering tasks identified for a lunar ISRU operations: (i) Excavation for oxygen production, (ii) Excavation and material handling for landing pad and berm fabrication, (iii) Excavation for habitat protection (ex. radiation and micrometeoroids), (iv) Excavation for mission element emplacement (ex. Nuclear reactor burial), and (v) Excavation for Science (ex. Trenching for stratigraphy evaluation). The most important task identified to date is regolith excavation and transport for oxygen production, since this is the first step in making oxygen on the Moon.

While the term 'excavation' brings to mind large and heavy machines and large mining sites, this is not the case for what is required to support early ISRU oxygen production rates that support in-situ production of oxygen for supplementing life 
support systems and for possible lunar ascent propulsion (1 to 10 metric tons of oxygen per year). However, there are significant challenges associated with regolith excavation and civil engineering on the Moon. Lunar regolith is extremely fine grained and abrasive raising significant wear concerns. Lunar regolith is extremely packed below the top layer of loosely consolidated material on the surface requiring vibration, ripping, and/or significant energy to perform the tasks required. The vacuum and low gravity environment along with the irregular shape and electrostatic properties of fine grain regolith also challenge terrestrial design techniques and models for excavation and material handling/flow. To support design and development of excavation and civil engineering hardware, the ISRU Project also initiated work in developing new computer models and laboratory/low-g aircraft test techniques to anchor and predict hardware performance.

Because establishing and operating a lunar base will require multiple missions to the same location, the terrain and long-term operation in the lunar dust environment raises several concerns that may need to be mitigated. For example, Apollo 12 landing near the Surveyor 3 spacecraft showed that dust projected by the Apollo Lunar Module rocket exhaust plume while landing caused abrasion and damage to the Surveyor 3 surface. It is not inconceivable that the higher landing thrust of proposed NASA crewed landers would cause even more damage to lunar habitat and power systems exposed to this dusty plume. To mitigate this hazard, fabrication of regolith berms or surface stabilization may be required. Also, because multiple landings will need to be performed, areas near the lunar base may need to be cleared of rock hazards so that landings can be performed with the minimum of risk. Therefore, the ISRU Project also initiated work on hardware and techniques associated with areas clearing, berm building, and surface stabilization for possible early civil engineering tasks.

\section{Fuel/Water Production from In-Situ Carbon Sources}

Besides hydrogen, hydrocarbon fuels such as methane are also of interest for propulsion and fuel cell applications for landers, hoppers, and mobile power systems. For long term sustainability, the need to recycle waste and create plastics and other feedstock for manufacturing, food, and chemical production is also of interest. Since the results from the LCROSS mission were not available at the start of the ISRU Project, work was initiated on how to convert trash and crew waste into usable products. Even if LCORSS hydrocarbon resources are available, it is important to have strategies for dealing with trash management. It was assumed that the trash and crew waste would be obtained from life support systems either in its original form or post processing to remove some of the water that might be in the trash/waste. Because Mars ISRU and the Carbothermal Reduction of regolith process deal with converting carbon monoxide/carbon dioxide into methane and other hydrocarbons, it was decided that the ISRU Project would focus on process such as pyrolysis, combustion, and steam reforming of trash/waste which were synergistic with other ISRU processing techniques.

\section{Lunar Simulant Development and Production}

Development and demonstration of lunar ISRU is only as good as the simulants 
used to test the feasibility and performance of the ISRU processes being developed. Because supplies of the previous lunar mare simulant, JSC-1, were almost depleted at the start of the ISRU Project and the ISRU project needed simulants right away to begin development tests, a new supply of JSC-1 was created as a bridge until simulants were available. Because actual lunar regolith contain glasses, agglutinates, nano-phase iron, solar wind volatiles, and minerals and mineral phases that could impact surface system operations, careful consideration of how 'realistic' the new simulants need to be verses the cost of producing them was required. It was also recognized that other simulants have been developed or could be developed by other organizations or industry, so a process to evaluate and standardize simulant characterization was deemed necessary. Led by the NASA MSFC, the approach taken in the ISRU Project to begin development of the new simulants was to: (i) Assess and understand users' needs, applications, quantities, and schedule, (ii) Define and develop simulant standards based on Apollo core samples, (iii) Define methods of measure for simulants (past, present, future), (iv) Evaluate simulant constituent production methods, and (v) Produce 'base' simulants and 'tailored' simulant blends at required quantities based on customer needs. Because lunar architecture studies pointed toward establishing a base at the lunar poles, focus was placed on developing a new series of simulants based on lunar highland mineralogy.

\section{ISRU DEVELOPMENT STRATEGY}

As was stated previously, while the concept of lunar ISRU has existed for over 40 years, the technology had not progressed much past simple, subscale laboratory proof-of-concept demonstrations. A focused, evolutionary approach to developing ISRU was required. At the start of the ISRU Project in ETDP, NASA initiated a four phased evolutionary development and integration strategy, with each phase lasting 1 to 3 years for each technology or capability area. Phase I involved demonstrating the feasibility of the concepts considered for human exploration missions at relevant mission scale, with Phase II aimed at increasing the performance and optimizing the processes involved once feasibility had been established. Phase III involved modification and testing in mission environments (gravity, temperature/solar, pressure/vacuum, and dust/regolith). The last phase, Phase IV, would involve reaching TRL 6 at or near flight mass, power, and volume for insertion into flight missions. Throughout this process, the development philosophy of 'build a little, test a lot, and modify to improve performance' was utilized such that each Phase may involve multiple generations of hardware and operations until key performance parameters and mission requirements are met.

For ISRU to be successfully integrated into mission architecture plans, all the steps required to achieve production of the final products need to be developed and demonstrated. Using terrestrial mining philosophy as a starting point, NASA and the Canadian Space Agency (CSA) have developed a Space ISRU 'Mining' Cycle (see Figure 1) to focus joint technology and integrated testing activities. The Space ISRU Mining Cycle starts with first locating and characterizing potential resources at the site of exploration from orbital and in-situ assets. These tasks should be planned and

performed in conjunction with Science organizations within space agencies since the goals and objectives of science and resource assessment are very synergistic. With 
this information, mining, site preparation, and processing systems and capabilities can be implemented. Processing and product storage requirements also have to be consistent with end 'customer' product quality, form, and quantity needs.

Besides developing and demonstrating all the steps in ISRU to find and process resources into useful products, it is important to understand and quantify the impact of ISRU on exploration system requirements, hardware, and operations. Therefore, efforts to link technology development and demonstration were made with surface mobility, propulsion, power, life support, and cryogenic storage and management projects within ETDP. A major emphasis was placed on the integration of fluid and energy product and distribution cycles for ISRU, power, propulsion, and life support systems, which is depicted in Figure 2.

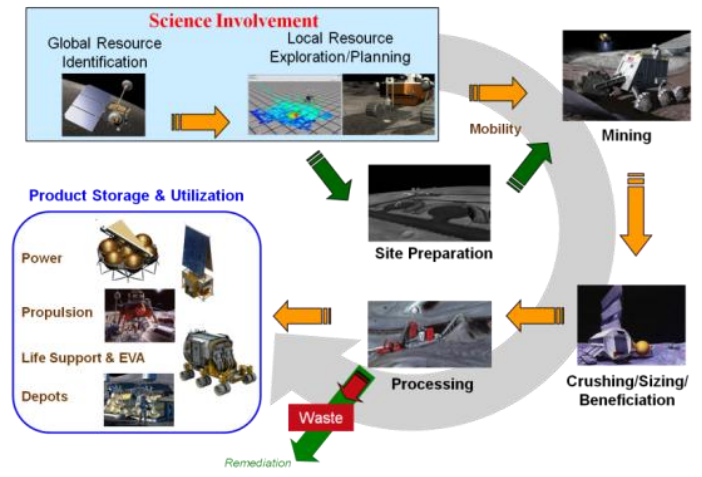

Figure 1. Space ISRU Mining Cycle

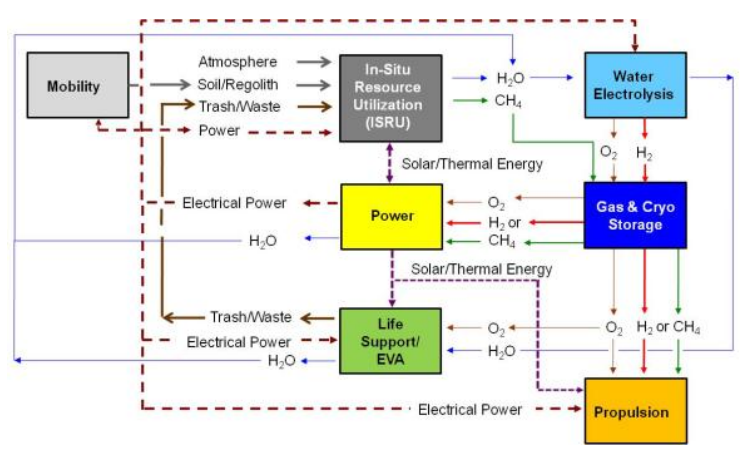

Figure 2. Integrated ISRU-Power-Propulsion-Life Support Fluid and Energy Cycles

\section{LUNAR ISRU DEVELOPMENT ACCOMPLISHMENTS IN ETDP}

During the five year existence of the ISRU Project in ETDP, significant progress was made in the state of the art of lunar ISRU technologies, systems, and capabilities. The ISRU Project raised the technology readiness level (TRL) of lunar ISRU technologies and capabilities from a low of 1-2 for concept and laboratory feasibility evaluation to a high of 4-5 for integrated system level tests and technology operation under $1 / 6-\mathrm{g}$ conditions during parabolic flights. Table 3 depicts the change in TRL for technology and system development in the ISRU Project.

It would not be possible to list all of the models, hardware, testing and lessonslearned accomplishments that have occurred over the five years of the ISRU Project. However the following are used to provide more insight into what was achieved besides simply raising the TRL 
Table 3. Lunar ISRU Technology Readiness Level Advancement in ETDP

\begin{tabular}{|c|c|c|c|}
\hline TRL increase in ETDP & At Start & At End & Delta \\
\hline \multicolumn{4}{|l|}{ System Level } \\
\hline Lunar Volatile Characterization (RESOLVE) & 1 & 5 & 4 \\
\hline $\mathrm{H}_{2}$ Reduction of Regolith & $2-3$ & 5 & $2-3$ \\
\hline $\mathrm{CH}_{4}$ Reduction of Regolith & $2-3$ & 5 & $2-3$ \\
\hline Molten Oxide Reduction of Regolith & 2 & 3 & 1 \\
\hline Trash Processing for Water/Methane Production & 2 & $2-3$ & $0-1$ \\
\hline \multicolumn{4}{|l|}{ Subsystem Level } \\
\hline \multicolumn{4}{|l|}{ Regolith Transfer \& Handling } \\
\hline Regolith Transport Into/Out of Reactor & 2 & 5 & 3 \\
\hline Beneficiation of Lunar Regolith & $2-3$ & $2-3$ & $0-1$ \\
\hline Size Sorting of Lunar Regolith & $2-3$ & $2-3$ & $0-1$ \\
\hline \multicolumn{4}{|l|}{ Oxygen Extraction From Regolith } \\
\hline $\mathrm{H}_{2}$ Reduction of Regolith Reactor & 3 & 5 & 2 \\
\hline Gas/Water Separation \& Cleanup & 2 & $4-5$ & $2-3$ \\
\hline $\mathrm{CH}_{4}$ Reduction of Regolith Reactor & 3 & 5 & 2 \\
\hline $\mathrm{CH}_{4}$ Reduction Methanation Reactor & $3-4$ & $4-5$ & $1-2$ \\
\hline MOE of Regolith Anode/Cathode & $1-2$ & $3-4$ & $2-3$ \\
\hline MOE of Regolith Molten Mat'l Removal & $1-2$ & 3 & $1-2$ \\
\hline MOE Cell and Valving & $2-3$ & 3 & $0-1$ \\
\hline \multicolumn{4}{|l|}{ Water/Fuel from Trash Processing } \\
\hline Trash Processing Reactor & 2 & $2-3$ & $0-1$ \\
\hline \multicolumn{4}{|l|}{ In-Situ Energy Generation, Storage, and Transfer } \\
\hline Solar Thermal Energy for Regolith Reduction & 2 & 5 & 3 \\
\hline
\end{tabular}

\section{Lunar Polar Ice/Volatile Resource Characterization and Subscale ISRU}

\section{Demonstration}

In 2005, the Regolith and Environment Science \& Oxygen and Lunar Volatile Extraction (RESOLVE) experiment development project was initiated to answer questions about the type, amount, and location of possible resources of interest (including water/ice) at the lunar poles, and to perform proof-of-concept and risk reduction demonstrations if a robotic mission opportunity became available. RESOLVE consists of a one meter coring drill that acquires subsurface regolith (developed in conjunction with CSA). The core sample is transferred, divided into individual segments, and each segment is examined for water/ice with a Raman or Infrared (IR) spectrometer. Regolith samples from the core drill are then transferred and heated in an oven in a step-wise manner to $150^{\circ} \mathrm{C}$ to measure the evolution of volatiles with a mass spectrometer and gas chromatograph (MS/GC). The MS/GC is designed to sense both solar wind volatiles like hydrogen, carbon, nitrogen, etc. as well as detect compounds like water, carbon monoxide, methane, or ammonia from comets that might have been trapped in the permanently shadowed craters. Once the volatile characterization portion of the experiment is complete, the oven's temperature can be raised to over $800{ }^{\circ} \mathrm{C}$ and $\mathrm{H}_{2}$ gas is introduced to perform the $\mathrm{H}_{2}$ Reduction reaction. The water evolved from volatiles and produced in the hydrogen reduction reaction is captured and viewed.

The RESOLVE project has taken a 'generational' approach to develop hardware toward a possible flight mission. A ${ }^{\text {st }}$ generation engineering breadboard unit (EBU) was built and laboratory tests were performed in 2007 to demonstrate the feasibility 
and design features of the hardware required to perform these tasks. Once this was completed, it was decided that a $2^{\text {nd }}$ generation EBU was needed to evaluate and demonstrate both the end-to-end operations required for a robotic mission as well as the packaging required to fit the hardware onto a rover. It was also decided to combine the volatile extraction and hydrogen reduction of regolith operations

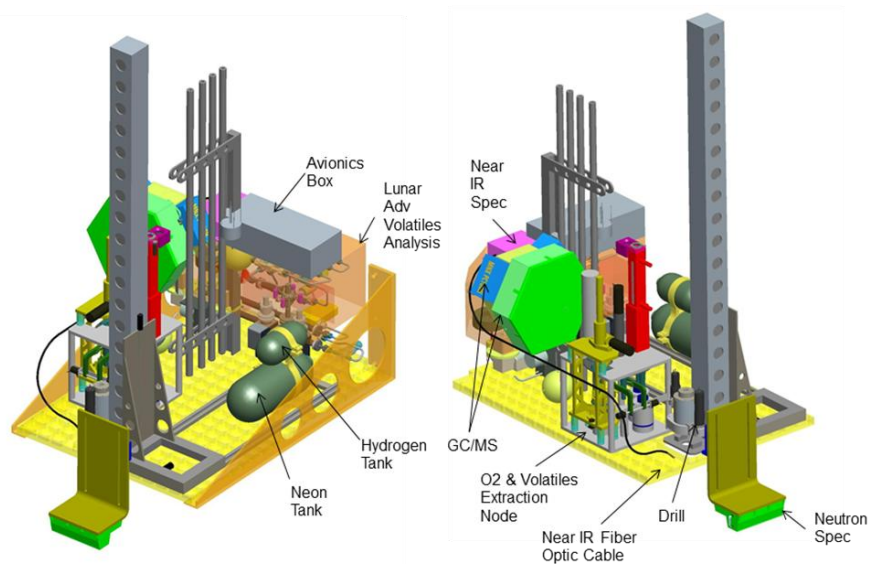

Figure 3. RESOLVE $3^{\text {rd }}$ Generation Design in a single reactor versus the separate reactor/oven approach utilized in the $1^{\text {st }}$ generation design [3]. This task was completed in November 2008 at a field test in Hawaii (see $1^{\text {st }}$ Lunar ISRU-Surface Operations Analog Field Test). The $2^{\text {nd }}$ generation EBU was $\sim 100 \mathrm{~kg}$ in mass and required 200 to 300 watts of power. No work was performed on miniaturizing the avionics and power conditioning subsystems, and due to cost, flight weight valves and motors were not utilized. All operational requirements for RESOLVE were met.

A $3^{\text {rd }}$ generation of RESOLVE was started in June 2010 aimed at designing a flight prototype that meets mission mass, power, and volume goals $(<60 \mathrm{~kg}$ and 200 watts average) and operates under applicable lunar environment conditions. The $3^{\text {rd }}$ generation of RESOLVE is being designed in two steps. Step 1 is a final integrated unit for analog mission simulation field testing in 2012, and Step 2 is a vacuum rated flight prototype scheduled for completion in 2014. Figure 3 depicts the $3^{\text {rd }}$ Generation Step 1 design for RESOLVE [4] which recently completed its critical design review (CDR).

\section{Oxygen Extraction from Regolith}

The ability to demonstrate the extraction and utilization of space resources for future human exploration is a major objective and rationale for NASA's human exploration of the Moon. Besides water, the next greatest resource of interest on the Moon is oxygen. As stated previously, the Hydrogen $\left(\mathrm{H}_{2}\right)$ Reduction process is the simplest and least efficient of the three oxygen extraction from regolith techniques examined. The ISRU Project initiated development of two lunar Outpost-scale $\mathrm{H}_{2}$ Reduction systems to allow comparison of different approaches for regolith feed and removal, regolith mixing and heating with $\mathrm{H}_{2}$, water vapor removal and collection, water electrolysis, and oxygen storage. The Lockheed Martin Astronautics (LMA) Precursor ISRU Lunar Oxygen Testbed (PILOT) system, started in 2005, used a 'cement mixer' approach with a tumbling reactor to mix and heat the regolith (see Figure 4c). The second concept, development by NASA, called ROxygen, used a vertical reactor which incorporated both fluidization and an internal auger to stir and heat the regolith (see Figure $4 \mathrm{a}$ ). The purpose of these $1^{\text {st }}$ generation hardware designs was not to build a system that meets flight mass or power requirements, but 
rather was intended to be the first end-toend integration and test of excavation, oxygen

production, and product storage in an automated system configuration at a relevant mission scale. Both PILOT and ROxygen system development

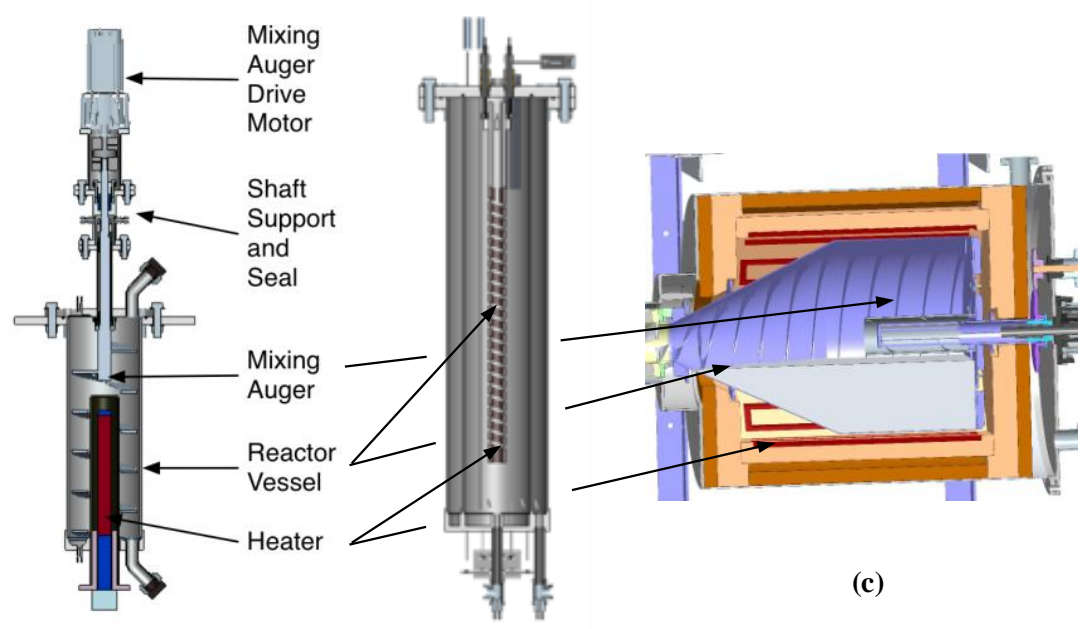

(a) (b)

Figure 4. (a) ROxygen Gen I Reactor, (b) ROxygen Gen II Reactor, (c) PILOT rotating reactor activities culminated with testing at an analog site in Hawaii in November 2008 (see $1^{\text {st }}$ Lunar ISRU-Surface Operations Analog Field Test). For $1^{\text {st }}$ generation designs, the test results from PILOT and ROxygen were positive. Both reactors evaluated production capabilities for various hydrogen flows and temperatures (between 875 and $1050{ }^{\circ} \mathrm{C}$ ), with oxygen extraction efficiencies around 1 to $2 \%$ by mass (i.e. 1 to $2 \mathrm{~kg}$ of oxygen for every $100 \mathrm{~kg}$ of bulk regolith). Extraction efficiency increased with increasing temperatures but regolith particle adhesion and sintering begins to occur at temperatures above $1000{ }^{\circ} \mathrm{C}$ which begins to cause issues with removing the material from the reactors after operations are completed [5]. Also, because both ROxygen and PILOT reactors proceed regolith batches which were two orders of magnitude greater than previous laboratory reactor tests $(10 \mathrm{~kg} \mathrm{vs}$ $>80 \mathrm{gms}$ ), it was found that besides creating water from iron-oxide materials in the regolith, hydrogen fluoride, hydrogen chloride, and hydrogen sulfide were also created in parts per million concentrations from constituents in the lunar regolith simulant. For long term operation and corrosion prevention, gas and water cleanup systems needed to be designed to scrub these contaminants from the gas and water products from the reactors. The PILOT reactor also included a regolith heat exchanger to recuperate heat from processed regolith to the next incoming batch of regolith, while time did not allow for a regolith heat exchange device for the $1^{\text {st }}$ generation of ROxygen.

Based on the $1^{\text {st }}$ generation system designs and results, a $2^{\text {nd }}$ generation ROxygen system based on utilizing pneumatic transport of regolith [6] and concentric chambers for regolith heat exchange were incorporated to minimize issues in the $1^{\text {st }}$ generation ROxygen for mass, regolith valving, regolith transport, and heat recuperation. Also, to increase oxygen extraction efficiency of the low performing $\mathrm{H}_{2}$ Reduction technique, a size sorting device was designed to increase fluidization and reaction rates [7], and an mineral beneficiation device was designed using a combined tribocharging/electrostatic separation technique to concentrate the iron-oxide in each batch of regolith processed [8]. While proof-of-concept and subsystem tests in the 
laboratory and on low-gravity parabolic flights were performed that showed all the subsystems for the ROxygen II were meeting performance goals, the final ROxygen Gen II system was not completed due to the cancellation of ETDP. Figure $4 b$ shows the ROxygen Gen II reactor design.

The Carbothermal Reduction process is a more efficient oxygen production technique compared to $\mathrm{H}_{2}$ Reduction because not only will it reduce the iron oxide but also some of the silicates found abundantly in the lunar regolith. However, the process requires much higher temperatures $\left(1800{ }^{\circ} \mathrm{C}\right)$ with the regolith becoming molten. A main challenge for this approach is delivering the energy needed to form the melt and developing techniques to deal with molten materials. Orbital Technologies Incorporated (Orbitec) developed a Carbothermal Reduction system under contract to LMA and NASA, and significant progress was made toward tackling these challenges. The Orbitec Carbothermal Reduction system design utilizes concentrated solar light channeled through fiber optic cables, development by Physical Science Inc (PSI) through Phase II and Phase III SBIR contracts, to melt the regolith and incorporates the ingenious concept of using the regolith's inherent insulation properties to contain the localized melts (see Figure 5). Once the reduction reaction is complete, the melts are allowed to cool, and once solid can be removed from the regolith bed with an automatic rake mechanism, thereby avoiding reactor wall material and molten material handling issues. The rake is then used to smooth the bed and prepare it for the next batch of oxygen production. The combined PSI solar concentrator system with Orbitec Carbothermal Reactor and NASA water electrolysis system was integrated and tested in 2010 as part of the $2^{\text {nd }}$ Lunar ISRUSurface Operation Analog Field Test [9,10].

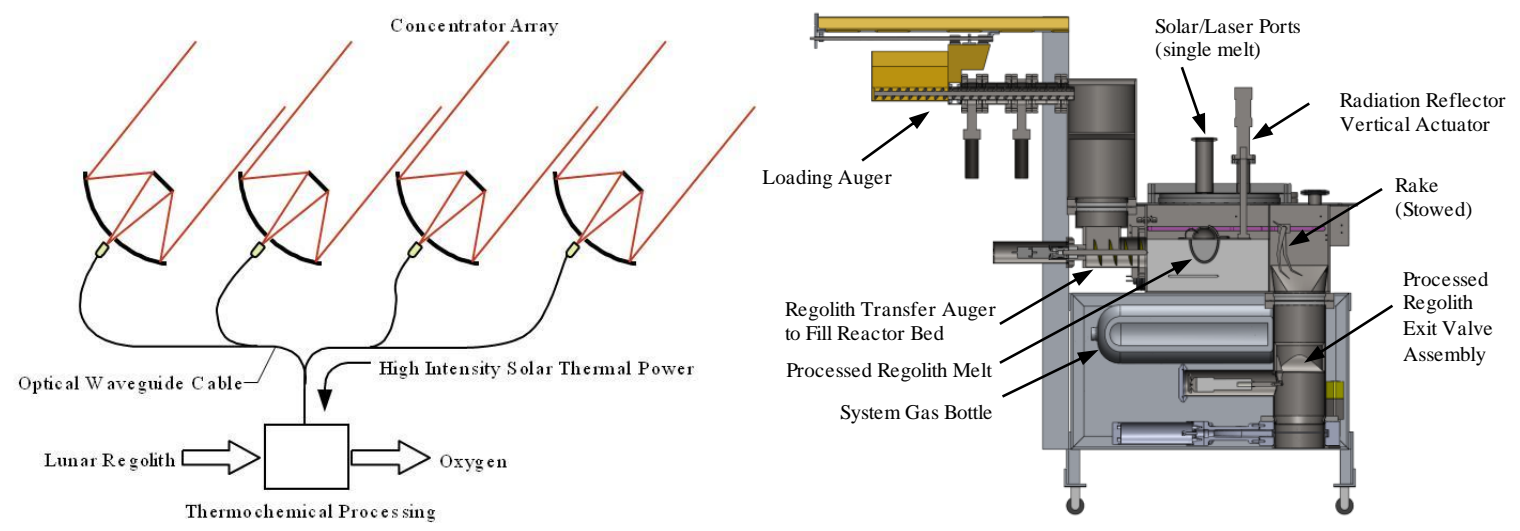

Figure 5. Solar Concentrator(left); CarbothermalReduction Reactor (right)

Regolith Excavation, Civil Engineering, and Surface Construction

When considering the Space ISRU Mining Cycle depicted in Figure 1, once resources have been located, they need to be excavated and transferred to the processing system for resource extraction. While there is tremendous terrestrial mining experience to leverage, there are several significant challenges to excavating and transferring regolith on the Moon. The first challenge is lunar regolith is made up of extremely fine, hard, oddly shaped, and abrasive material. The second challenge is the lunar environment which encompasses $1 / 6^{\text {th }}$ Earth's gravity, vacuum, and extreme temperature differences possible on the surface. The third challenge is mass and 
power are limited compared to terrestrial applications. All of these challenges combined raise significant issues with equipment life as well as the excavation and flow of granular material under these environmental conditions.

Before the ISRU Project initiated any efforts to design and build $1^{\text {st }}$ generation excavation or area clearing implements, it was decided that basic research and models would be developed on regolith behavior, flow, and granular material/implement interaction to anchor $1^{\text {st }}$ generation hardware design and performance evaluation. Early in the project, a replica of the Surveyor spacecraft excavator from the Apollo program was recreated and tested in the laboratory to help anchor these models. Subsequent tests were also performed on blades, bucketwheels, and scoop excavators in prepared regolith bins at the Glenn Research Center (GRC) (see Figure 6). At the same time, work was initiated on analytical and Discrete Element Method (DEM) computer models of regolith granular material behavior $[11,12]$.

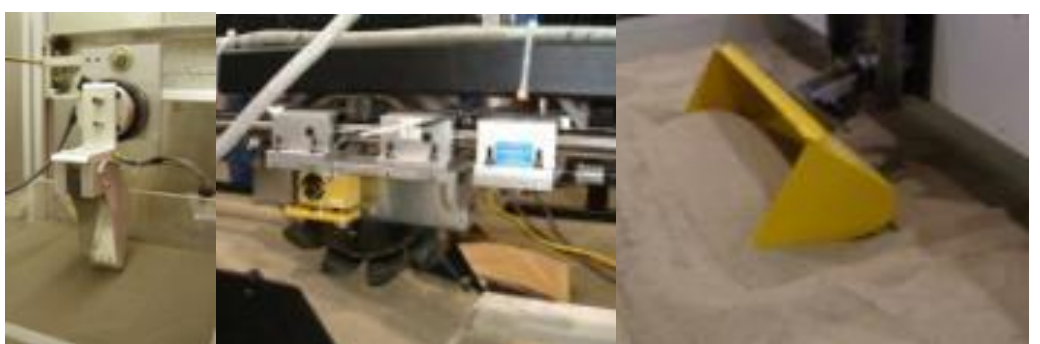

Figure 6. Laboratory Testing of Exca vation \& Area Clearing Implements

There is a general misconception based on artistic representations of lunar ISRU systems, that large excavators are required. Based on excavation models as well as work on oxygen extraction from regolith techniques, it was determined that very small excavators could be utilized to meet the oxygen production needs of 1000 to $10,000 \mathrm{~kg}$ per year for early human lunar mission concepts. Based on the lowest performing oxygen extraction from regolith technique $\left(\mathrm{H}_{2}\right.$ Reduction), excavators only have to excavate a soccer field sized area $8 \mathrm{~cm}$ deep over 1 year to produce $10,000 \mathrm{~kg}$ of oxygen. This fact, associated with the desire to minimize excavator mass and power and dispel misconception of ISRU system size, the ISRU Project and external developers focused on designing and build small excavator concept vehicles.

Two separate small excavator concept vehicles were designed, built, and tested in 2007-08. One concept, known as 'Cratos', was built by GRC and tested under controlled laboratory and field test conditions. Cratos weighed about $80 \mathrm{~kg}$, is a little under a meter square, and can deliver an average load of $23 \mathrm{~kg}$ of regolith per trip to the oxygen production system's regolith hopper. The second demonstration unit, known as the bucketdrum excavator, was designed and built under IR\&D by LMA in Denver. While the bucketdrum mobility platform was not designed for actual lunar surface conditions, the bucketdrum demonstrated excellent excavation and material transport capabilities for minimal mass and power. The bucketdrum could excavate $\sim 18 \mathrm{~kg}$ in 3 minutes. To produce $1000 \mathrm{~kg}$ of oxygen using the $\mathrm{H}_{2}$ Reduction technique, based on an average load of $20 \mathrm{~kg}$ (which either concept vehicle could provide), a small excavator would only need to make twelve excavation runs per day to harvest the necessary regolith. Since this can easily be accomplished by these concept vehicles in just a few hours per day, the concept vehicles provided an important visual understanding to mission planners that ISRU infrastructure to support human lunar missions does not have to be massive. Figure 7 depicts the 


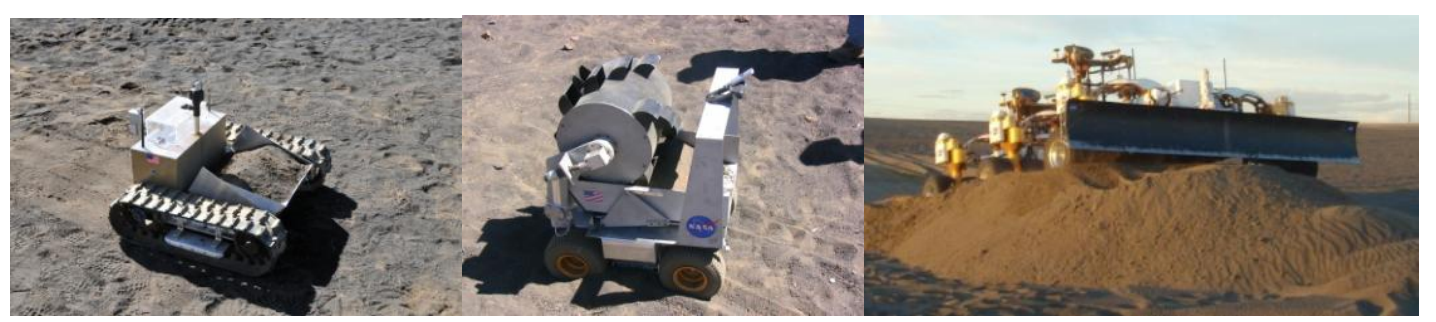

Figure 7. Cratos Excavator(left); Bucketdrum Excavator(middle), LANCE on Chariot (right)

Cratos and Bucketdrum excavators during a field test in Hawaii.

From terrestrial mining experience, civil engineering tasks such as building roads between excavation sites and processing systems, can be very important to minimize vehicle maintenance and travel time. Also, mining infrastructure placement and operations for buildings, helipads, and logistic depots require civil engineering and area clearing capabilities. As shown in the Space ISRU Mining Cycle, site preparation capabilities for road construction, outpost infrastructure placement, and cleared areas for lunar landers are expected to be needed for future human lunar missions. Unlike excavation for oxygen extraction from regolith, should site preparation/civil engineering tasks be undertaken, substantially more lunar regolith must be moved and handled in a shorter period of time to clear areas for landing pads and roads and build berms for landing plume mitigation. Also, these tasks may require excavation below the loosely consolidated top material and the removal and handling of rocks. ISRU Project personnel at the Kennedy Space Center (KSC) in collaboration with the Human Robotic System (HRS) Project in ETDP developed a "bulldozer" blade, called LANCE (Lunar Attachment Node for Construction and Excavation) that could be used to move large amounts of soil and be attached to the HRS 'Chariot' crew rover. This proof-of-concept project was intended to be a final design for the architecture, but rather an opportunity for two ETDP projects to begin to work together and understand the integration and operation issues for site preparation implements attached to a mobility platform. Because autonomous blade control software was not developed for this effort, performance of the LANCE blade was strongly influenced by the controller's manual abilities to control the blade before wheel slippage occurred. Figure 7 depicts the LANCE blade attached to the Chariot rover during field test operations at Moses Lake in 2008 [13].

\section{ISRU Development Support}

As stated previously, development of lunar ISRU technologies and capabilities is only as good as the simulants used to test the feasibility and performance of the ISRU processes being developed. While it was recognized that JSC-1 was a reasonable physical and mineral simulant for early feasibility development efforts, it fell short of actual lunar regolith in several physical and mineral characteristics that are important for understanding regolith flow and life/abrasion as well as energy and reaction rates for oxygen extraction. To overcome these deficiencies, the MSFC with support from the US Geological Survey and Zybek Advanced Products created a series of lunar highland simulants known as NU-LHT (for NASA-ㅡS Geological Survey Lunar Highland Type). This simulant series includes more realistic particle size/shape distributions, glasses and agglutinate material, and mineral feedstock in comparison 
to previously developed lunar simulants [14]. The primary drawback to LHT lunar simulants have been the cost and small amount of simulant produced to date.

To minimize ISRU system mass and power, ISRU systems are designed to be pre-deployed and operate for long periods of time on planetary surfaces before crew arrive. To understand life issues and verify performance and operation before flight, the ISRU Project planned on utilizing a combination of laboratory, analog field test, and environment/vacuum simulation chambers during development of ISRU technologies and capabilities. At the start of the ISRU Project, no vacuum chamber existed inside or outside of NASA that could simulate lunar environmental conditions (vacuum, temperature, and solar) with regolith in the chamber. Early work by Lockheed Martin with IR\&D showed that it was possible to have a vacuum chamber with regolith but that the regolith continued to outgas upon agitation. Also, the regolith impacts the operation of thermal control and vacuum facility hardware. A series of tests were planned to incrementally increase the understanding of the issues and challenges of setting up a large simulant bed inside a vacuum chamber and operating the environment simulation chamber for extended periods of time. These tests, performed at JSC and GRC, included permeability, facility component protection, soil drying and compaction, soil bed characterization methods and instruments, and controlled moisture dosing techniques. One set of tests examining regolith dust buildup in roughing and diffusion pump oil showed that 2 to 3 gms of dust were added to the oil and that in-line filtration would be required for long duration tests. Tests are currently being performed at GRC on evaluating soil compaction techniques to prepare regolith beds before and after vacuum conditions have been achieved in the chamber [15].

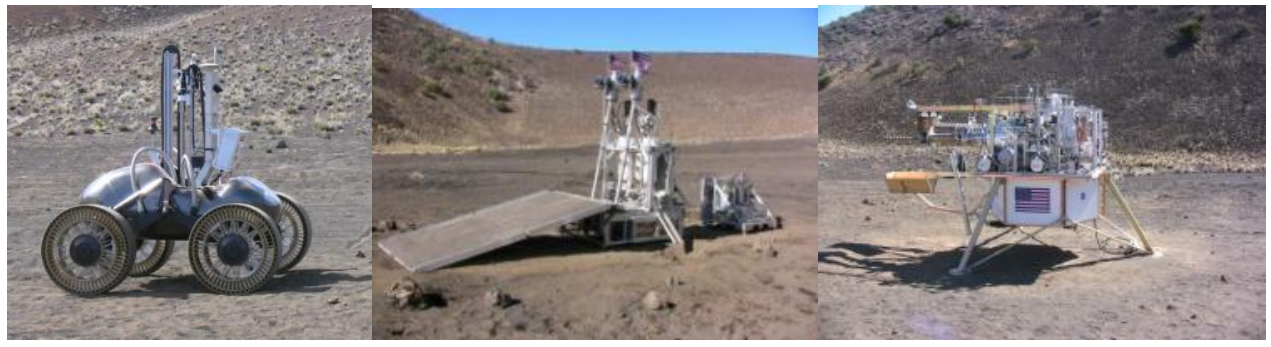

Figure 8. RESOLVE/Scarab (left), ROxygen System (middle); PILOT system (right)

\section{$\underline{1^{\text {st }} \text { Lunar ISRU-Surface Operations Analog Field Test }}$}

A major impediment to incorporating ISRU capabilities into lunar architecture plans has been the fact that ISRU systems have not been demonstrated either at a complete system level or out of the laboratory. To begin to remove this impediment, the purpose of the first ISRU-Surface Operations Analog Field Test was to (i) perform the first end-to-end test of excavation, oxygen production, and product storage in an integrated system configuration at a relevant scale for future human lunar missions, (ii) demonstrate prototype hardware and operations associated with mobile resource prospecting to prove the feasibility for a future lunar polar mission, and (iii) develop partnerships with international space agencies and Hawaii. The first analog field test was performed in November 2008 on Mauna Kea in Hawaii to coincide with the Japan US Science, Technology, \& Space Applications Program (JUSTSAP) conference. 
To support the analog field test goals and objectives, three major ISRU systems were developed by NASA and industry/academia partners; a roving lunar polar resource characterization system called RESOLVE/Scarab, and two $\mathrm{H}_{2}$ Reduction from regolith systems; ROxygen and PILOT (see Figure 8). The CSA provided support to the RESOLVE/Scarab system for sample acquisition, drill site selection, and nighttime navigation as well as providing on-site and satellite communication between Hawaii and the mainland for the analog field test effort. The German Space Agency (DLR) also participated in the field test by testing their lunar mole prototypes and a Mossbauer spectrometer for mineral evaluation before and after oxygen extraction processing.

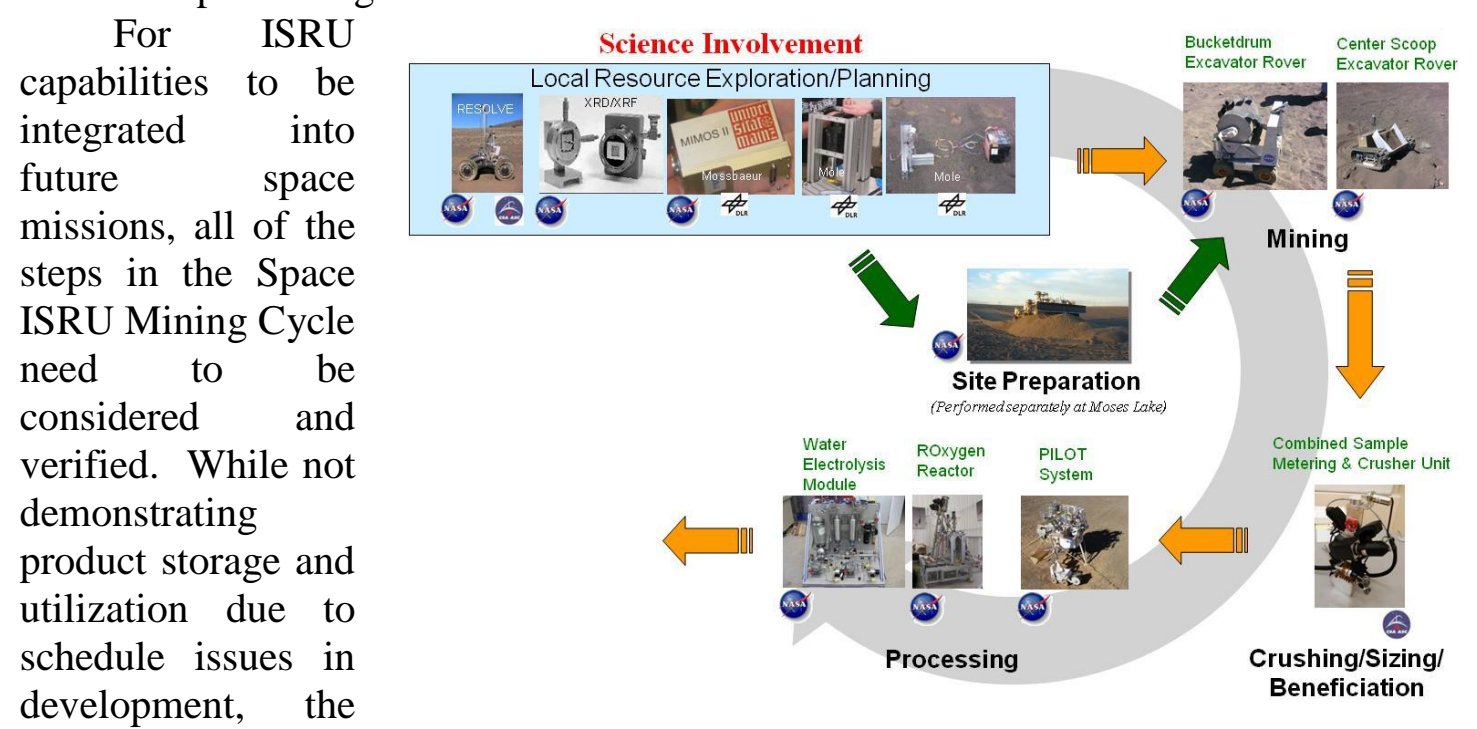

$1^{\text {st }} \quad$ ISRU-Surface

Operations analog

Figure 9. Hardware and Participants in the $1^{\text {st }}$ ISRU-Surface Operation

Ana log Field Test

field test was a

major success in that it succeeded in demonstrating for the first time the Space ISRU Mining Cycle (see Figure 9) even if all hardware operations were not achieved. The field test was the first demonstration of lunar ISRU end-to-end operations at mission relevant scales. The ROxygen system produced oxygen at a $660 \mathrm{~kg} / \mathrm{year}$ rate and the PILOT system produced oxygen at a $250 \mathrm{~kg} / \mathrm{year}$ rate (initial lunar outpost needs were estimated to be $1000 \mathrm{~kg} /$ year). The PILOT system completed 6 reactor operations and produced $1000 \mathrm{ml}$ of water from iron-oxide in the local volcanic tephra material while the ROxygen system completed 5 reactor operations. The RESOLVE/Scarab system completed 6 core sample drillings, 6 sample volatile characterizations, and 4 oxygen extraction from regolith operations $[16,17,18,19]$. Since the gas/water cleanup system for ROxygen and PILOT had not been adequately tested and verified before the field test, neither ISRU system electrolyzed the water produced from the local tephra material. All systems in ROxygen and PILOT were operated successfully with deionized water, and post test analysis of the water produced from tephra after passing through the water cleanup system confirmed that the cleaning technique developed was successful. All in all, 5 NASA centers, 2 international space agencies, 7 companies, and 2 universities participated in the analog field test. 
$\underline{2^{\text {nd }} \text { Lunar ISRU-Surface Operations Analog Field Test }}$

Even before the $1^{\text {st }}$ Lunar ISRU-Surface Operations analog field test was completed, development of improved and $2^{\text {nd }}$ generation hardware was already underway for subsequent testing. Because of the success in testing ISRU capabilities, demonstrating the major steps in the Space ISRU Mining Cycle, and involving international, industry, and academic partners at the first analog field test, it was decided to increase the scope and complexity of the next analog field test. With this in mind, NASA and CSA directed efforts for the second ISRU and Lunar Surface Operations analog field test to (i) advance ISRU hardware and systems demonstrated over $1^{\text {st }}$ analogue field test, (ii) expand ISRU system/capability integration with other transportation and surface elements (such as power and propulsion) and science activities, and (iii) increase the scope and criticality of international partner involvement in ISRU development and demonstration. The $2^{\text {nd }}$ Lunar ISRU-Surface Operations

analog field test was performed in January and February of 2010 at the same location on Mauna Kea in Hawaii as the first field test, and involved demonstrating instruments, hardware, and operations in all steps of the Space ISRU Mining Cycle. This included testing

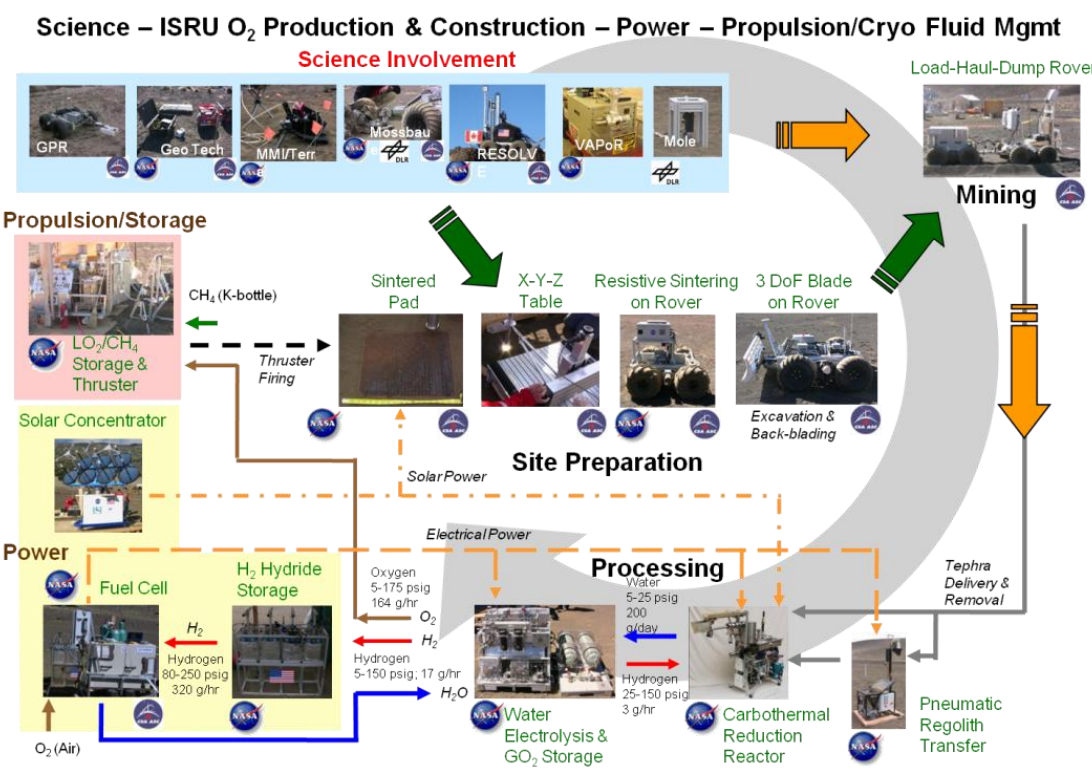

Figure 10. Space Mining Cycle Hardware Integration and Operation in the $2^{\text {nd }}$ ISRU-Surface Operation Analog Field Test

an upgraded RESOLVE lunar polar resource characterization package on a CSA provided rover [20] and other science instruments provided by CSA and NASA's Moon Mars Analog Mission Activity (MMAMA), an integrated Carbothermal reduction of regolith production system with solar concentrator regolith heating, water electrolysis, liquid oxygen/ methane storage, and liquid oxygen/methane thruster. The NASA ISRU hardware was powered by a CSA provided fuel cell. Site preparation tasks were performed by NASA and CSA demonstrations of autonomous landing pad, road, and berm building capabilities along with solar concentrator and resistive heating surface sintering (see Figure 10).

The $2^{\text {nd }}$ ISRU-Surface Operation analog field test was considered even more successful than the first field test. In this field tests, all aspects of ISRU and lunar surface system integration were tested in an end-to-end manor, which led to it being referred to as 'Dust to Thrust' [21]. This including autonomous/tele-operation of a Load-Haul-Dump rover excavator (CSA provided) [22], extracting 28 gms of oxygen 
from the local tephra using the more efficient Carbothermal reduction processing technique (9.6\% ave yield) in 12 operations (NASA provided) [23], electrolyzing water produced from the tephra and fuel cell power system (NASA provided), transferring and liquefying oxygen in a cryocart (NASA provided), sintering surface pads using two different methods (CSA and NASA provided), and firing a liquid oxygen/methane thruster (with oxygen produced in-situ) onto unprepared and sintered surfaces to evaluate plume effects on the surface (NASA provided). As depicted in Figure 2, the $2^{\text {nd }}$ ISRU-Surface Operation analog field test also strived to close the propulsion and ISRU-power cycles with the production and storage of hydrogen and oxygen (NASA and CSA provided) from the water electrolyzer being used in a fuel cell (CSA provided) [24] to power the rover excavator, and oxygen produced being used in the thruster firings. By closing both the propulsion and power system cycles, the field test successfully demonstrated integration of ISRU and surface/transportation elements. More importantly, hardware from both CSA and NASA was required to successfully close the ISRU-Power and ISRU-Propulsion cycles, thereby meeting the programmatic objective of demonstrating international partnerships in mission critical operations. All in all 6 NASA centers, 3 Canadian government agencies, 14 small businesses, and 7 universities participated in the $2^{\text {nd }}$ analog field test.

\section{CONCLUSION}

Incorporation of ISRU and the production of mission critical consumables for propulsion, power, and life support into mission architectures can greatly reduce the mass, cost, and risk of missions leading to a sustainable and affordable approach to human exploration beyond Earth. ISRU and its products can also greatly affect how other exploration systems are developed, including determining which technologies are important or enabling. While the concept of lunar ISRU has existed for over 40 years, the technologies and systems had not progressed much past simple laboratory proof-of-concept tests. With the release of the Vision for Space Exploration in 2004 with the goal of harnessing the Moon's resources, NASA initiated the ISRU Project in the Exploration Technology Development Program to develop the technologies and systems needed to meet this goal. In the five years of work in the ISRU Project, significant advancements and accomplishments occurred in several important areas of lunar ISRU. Also, two analog field tests held in Hawaii in 2008 and 2010 demonstrated all the steps in ISRU capabilities required along with the integration of ISRU products and hardware with propulsion, power, and cryogenic storage systems. These end-to-end demonstrates were performed at relevant human missions scales show that incorporation of lunar ISRU into mission plans is achievable.

\section{ACKNOWLEDGMENTS}

The authors would like to acknowledge all of the men and women in NASA, industry (both US and international), academia, and partnering space agencies for all of the hard work and dedication that went into turning lunar ISRU concepts into reality. It is because of their efforts that ISRU is now more than just 'viewgraph' engineering. 


\section{REFERENCES}

[1] Lunar Sourcebook a user's guide to the moon, edited by Grant Heiken, David Vaniman, and Bevan French, Lunar Planetary Institute

[2] Data obtained from Tony Colaprete, Principle Investigator for the Lunar Crater Observation \& Sensing Satellite (LCROSS) mission.

[3] Julie Kleinhenz, Zengguang Yuan, John Caruso, and Kurt Sacksteder, "Development of a Reactor for the Extraction of Oxygen and Volatiles from Lunar Regolith", 47th AIAA Aerospace Sciences Meeting, Orlando, FL, Jan. 2009.

[4] William Larson, Martin Picard, Gerald Sanders, Anthony Colaprete, and Richard Elphic, "RESOLVE: Ground Truth for Polar Lunar Volatiles as a Resource", 62nd International Astronautical Congress, Cape Town, SA, Oct. 2011.

[5] Larry Clark, "Precursor In-Situ Lunar Oxygen Testbed (PILOT) Hawaii Field Testing Nov 2008”, Panel Presentation, AIAA Space 2009, Pasadena, CA., Sept. 2009

[6] Edgardo Santiago-Maldonado, James Mantovani, and Jesus Dominguez, "Experimental Testing and Modeling of a Pneumatic Regolith Delivery System for ISRU", Presentation at Planetary and Terrestrial Mining and Sciences Symposium (PTMSS), Ottawa, Canada, June, 2011.

[7] Allen Wilkinson, "Size Beneficiation of Regolith for Simplicity and Efficiency", Presentation at Planetary and Terrestrial Mining and Sciences Symposium (PTMSS), Ottawa, Canada, June, 2011.

[8] Steve Trigwell, James Captain, Ellen Arens, et. al., "The Use of Tribotcharging in the Electrostatic Beneficiation of Lunar Simulant", IEEE Transactions on Industry Application, Vol. 45, No. 3, May/June 2009.

[9] Brant White, Robert Gustafson, and Michael Fidler, "2010 Field Demonstration of the Solar Carbothermal Regolith Reduction Process to Produce Oxygen”, 49th AIAA Aerospace Sciences Meeting, Orlando, FL, Jan. 2011

[10] T. Nakamura and B. Smith, "Solar Thermal Power System for Lunar ISRU Applications: Development and Field Operation at Mauna Kea, HI", AIAA 49th Aerospace Science Meeting, Orlando FL, Jan. 2011.

[11] Diane Linne, Christopher Gallo, Aaron Joseph, "Preliminary Trade Study on Scoop Size for large Excavation Vehicle", Presentation at Planetary and Terrestrial Mining and Sciences Symposium (PTMSS), Toronto, Canada, June, 2009.

[12] Christopher Gallo, "A Comparison Between the NORCAT Rover Test Results and the ISRU Excavation System Model Predictions", Presentation at Planetary and Terrestrial Mining and Sciences Symposium (PTMSS), Ottawa, Canada, June, 2011.

[13] Robert Mueller, Allen Wilkinson, Christoper Gallo, et. al., "Lightweight Bulldozer Attachment for Construction and Excavation on the Lunar Surface", AIAA Space 2009, Pasadena, CA., Sept. 2009. 
[14] Diane Linne, "Requirements and Progress Towards a Planetary Surface Simulation Facility", Presentation at Planetary and Terrestrial Mining and Sciences Symposium (PTMSS), Ottawa, Canada, June, 2011.

[15] D. Stoeser, S. Wilson, and D. Rickman, "Design and Specifications for the Highland Regolith Prototype Simulants NU-LHT-1M and -2M", NASA/TM2010-216438, August, 2010.

[16] Robert P. Mueller and Ivan Townsend, "Lunar Regolith Simulant Feed System for a Hydrogen Reduction Reactor System", 47th AIAA Aerospace Sciences Meeting, Orlando, FL, Jan. 2009.

[17] Gerald B. Sanders, William E. Larson, Thomas Simon, et. al., "NASA In-Situ Resource Utilization Program", AIAA 2009-0412, 47th AIAA Aerospace Sciences Meeting, Orlando, FL, Jan. 2009.

[18] Julie Kleinhenz, Zengguang Yuan, John Caruso, and Kurt Sacksteder, "Development of a Reactor for the Extraction of Oxygen and Volatiles from Lunar Regolith", 47th AIAA Aerospace Sciences Meeting, Orlando, FL, Jan. 2009.

[19] Anthony C. Muscatello, "Lunar Water Resource Demonstration (LWRD)", 47th AIAA Aerospace Sciences Meeting, Orlando, FL, Jan. 2009.

[20] Janine Captain, "RESOLVE 2010 Field Test”, Space Resources RoundtablePlanetary and Terrestrial Mining and Sciences Symposium (SRR-PTMSS), Golden, CO., June, 2010.

[21] Sanders, Gerald, Larson, William, "Integration of In-Situ Resource Utilization Into Lunar/Mars Exploration Through Field Analogs", 38th COSPAR Scientific Assembly, Bremen, Germany, July 2010.

[22] Dale S. Boucher, J Tom Atwell, Ronny Theiss, "Development and Testing of an Autonomous Regolith Excavation and Delivery System", 49th AIAA Aerospace Sciences Meeting, Orlando, FL, Jan. 2011.

[23] Brant White, Robert Gustafson, and Michael Fidler, "2010 Field Demonstration of the Solar Carbothermal Regolith Reduction Process to Produce Oxygen", 49th AIAA Aerospace Sciences Meeting, Orlando, FL, Jan. 2011.

[24] Jim Richard, Ravi Gopal, Dale S. Boucher and Ronny Theiss, "Fuel Cell Integration to a Mobility Platform", 49th AIAA Aerospace Sciences Meeting, Orlando, FL, Jan. 2011. 